\title{
Testes Psicológicos: Análise da Produção Científica Brasileira no Período 2000-2004
}

Psychological tests: An analysis of the brazilian scientific production between 2000 and 2004
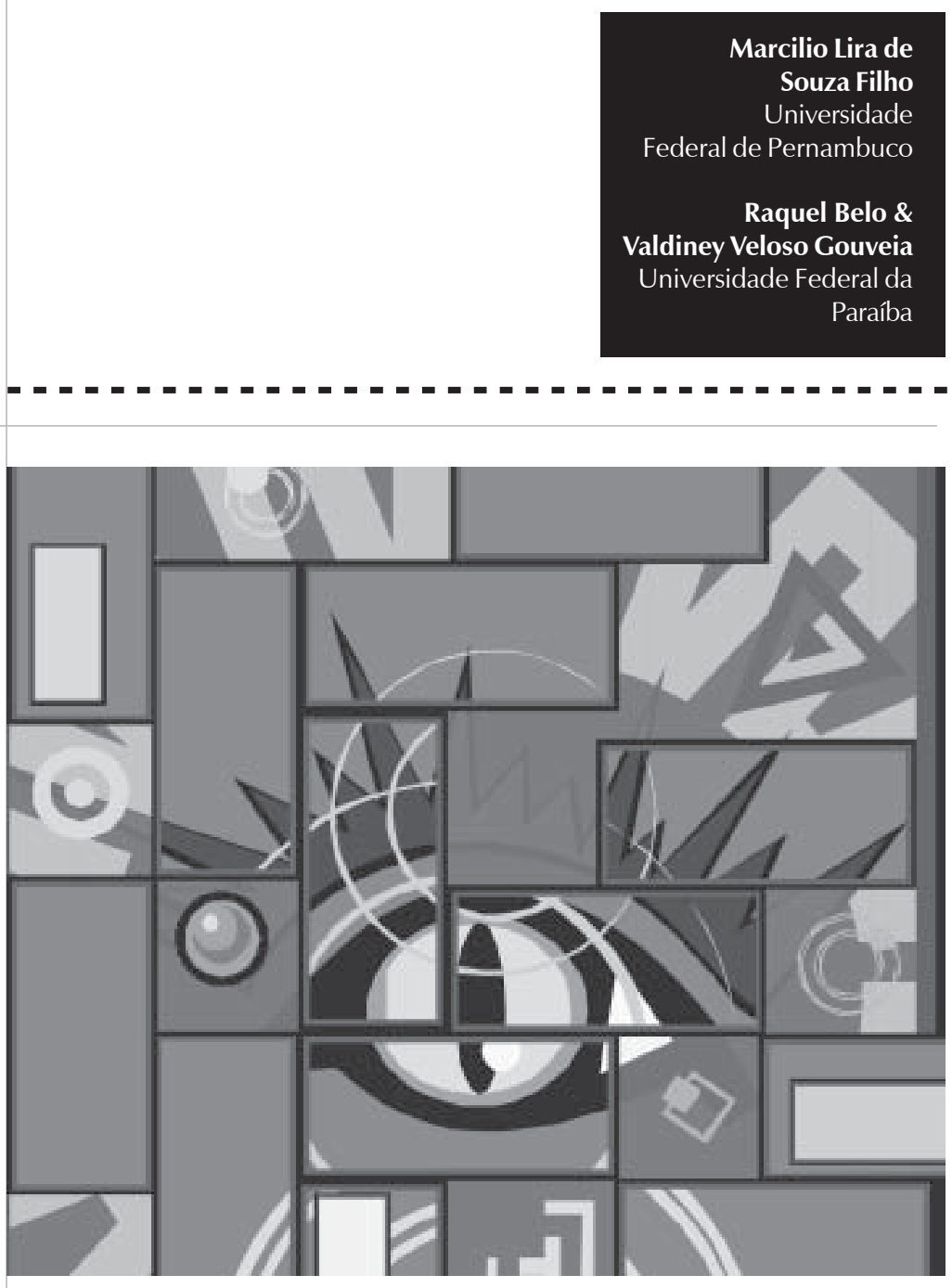


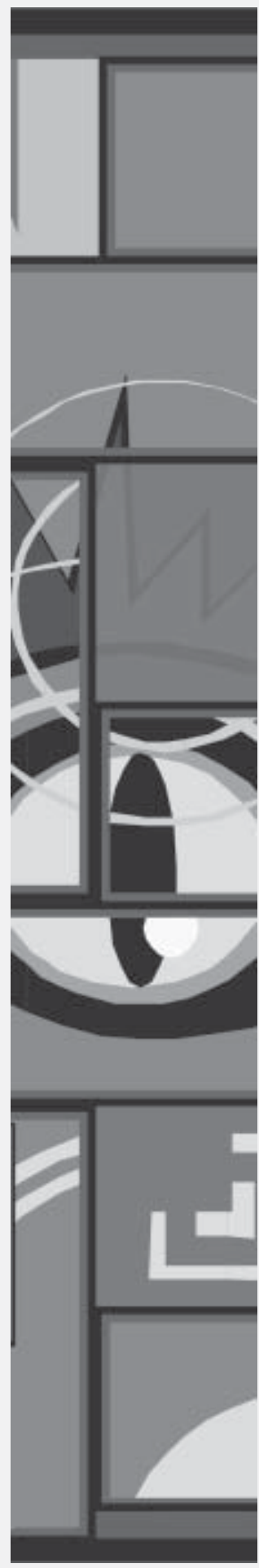

Resumo - Este estudo buscou traçar o perfil da utilização dos testes psicológicos na literatura científica brasileira nos últimos anos. Foram analisados artigos de periódicos brasileiros, entre os anos de 2000 e 2004, disponíveis na base de artigos Periódicos Capes em fevereiro de 2005. Os principais resultados demonstraram predominância dos artigos que não consideram nenhum teste. Dentre os que consideram, há uma equivalência entre aqueles que utilizam os testes de forma direta e indireta, sendo a maioria deles de natureza empírica. A maior concentração dessas produções está situada na Região Sudeste. Em temos institucionais, as universidades mais produtivas foram as federais e privadas, sobretudo aquelas que têm um histórico pautado pelo interesse na área da avaliação psicológica. Conclui-se, de forma geral, que a utilização dos testes psicológicos no contexto da produção nacional ainda é modesta e está, em grande parte, restrita aos âmbitos acadêmicos mais intensamente dedicados ao estudo dos testes.

Palavras-chave: testes psicológicos, produção científica, artigos nacionais, estudo bibliométrico.

Abstract: This study aims to delineate the profile of the psychological test usage in Brazilian scientific literature in the last few years. To reach this goal, the production analyzed was made up of all the articles published in Brazilian periodicals from 2000 to 2004, available in the Capes Periodicals article base during the first two weeks of February 2005. The main results demonstrate the predominance of articles that take no psychological tests into consideration. Among the articles that take them into consideration, there is an equivalence among the articles that use the tests directly and those that use them indirectly, and most of the articles have an empirical orientation. The greatest concentration of this type of production comes from the southeast region of Brazil. In institutional terms, the most productive universities were the federal and private ones, especially those that have a demonstrated interest in the area of psychological evaluation. We came to the conclusion that, generally speaking, the use of psychological testing in the context of Brazilian scientific production is still modest and largely restricted to the academic areas most intensely dedicated to the study of tests.

Key words: psychological tests, scientific production, Brazilian articles, literature review. 
Desde o início da Psicologia enquanto disciplina científica, sempre foram uma constante as tentativas de realizar objetivamente diferenciações de variáveis psicológicas. Nesse contexto, surgiram os testes psicológicos, que assumiram, ao longo dos anos, um caráter emblemático da Psicologia e justificam, até certo ponto, a associação entre a figura do psicólogo e a administração de testes realizada pelo grande público.

Um teste psicológico é um instrumento de medida, um procedimento por meio do qual se busca medir um fenômeno psicológico (Van Kolck, 1974), estando nele resumidas amostras de comportamentos relacionados a uma variável psicológica. Nesse sentido, Anastasi e Urbina (2000) definem um teste psicológico como a medida padronizada e objetiva de uma amostra comportamental. Isso significa dizer que um teste que busca medir a ansiedade, por exemplo, deve conter questões que contemplem todo o contínuo do conceito ansiedade. De maneira geral, um teste psicológico se presta a medir diferenças entre indivíduos ou as reações do mesmo sujeito em momentos diferentes (Anastasi; Urbina, 2000). Esse aspecto funcional dos testes possibilitou e ainda favorece muito a amplificação dos conhecimentos em Psicologia que se baseiam essencialmente em evidências empíricas e não apenas em meras especulações.

Os testes psicológicos têm fornecido contribuições tanto no campo teórico, em pesquisas básicas e aplicadas, como também no campo prático, onde são fundamentais na realização de diagnósticos, seleções e classificações, orientações e treinamentos. De acordo com Tyler (1973), as medidas psicológicas, a partir do momento em que, via teoria, quantificam as variáveis com as quais se trabalha, constituem-se em caracterizadores preponderantes da Psicologia moderna. Tal observação (feita nos Estados Unidos há pouco mais de três décadas) demonstra o quanto o pensamento quantitativo constitui uma das características essenciais e não periféricas da Psicologia. Será que hoje, aqui no Brasil, isso também se aplicaria?

Diante dessa questão, remetendo-se ao processo de profissionalização do psicólogo brasileiro, pode-se dizer que o interesse pelos testes psicológicos freqüentemente esteve presente (Pereira; Neto, 2003). Estes foram importantes em um período "pré-profissional" (1833-1890), posto que, além de suas vantagens funcionais, ajudava a conferir um estatuto de cientificidade à nova disciplina. Em seguida, ao longo do "período de profissionalização" (19901975), a testagem e as dimensões mensurativas e classificatórias estiveram fortemente presentes como caracterizadoras da prática do psicólogo. Nessa mesma direção, Rosas (1998), ao analisar os discursos psicológicos presentes nas reuniões da Sociedade Brasileira para o Progresso da Ciência (SBPC), aponta o acentuado volume de trabalhos relacionados à psicometria e aos testes psicológicos entre os anos de 1940 e 1968, época em que a utilização de testes era hegemônica na prática dos psicólogos.

Um ponto interessante a ser mencionado é que, em sua análise do processo de profissionalização do psicólogo brasileiro, Pereira e Neto (2003), ao tratarem do "período profissional" propriamente dito, situado entre 1975 até os dias atuais, não mais mencionaram os testes e/ ou atividades mais diretamente relacionadas ao seu uso, e argumentam que o período mais recente é marcado pelo predomínio da psicoterapia realizada em consultórios particulares. Ter-se-á tratado de mero esquecimento ou essa desconsideração é reflexo de uma minimização da importância atribuída a esse material?

Pasquali (1999), ao considerar os instrumentos de avaliação psicológica como essenciais para o progresso do conhecimento psicológico brasileiro, faz uma séria crítica aos psicólogos e pesquisadores que não lidam adequadamente, ou mesmo têm pouco interesse na sua 
utilização, e atribui tal situação a uma deficiência na formação profissional, que não capacitaria a contento os profissionais da Psicologia no manejo desse material. Entretanto, por outro lado, alguns esforços hoje empreendidos a favor dos testes demonstram que existe um interesse manifesto por grupos de profissionais bastante qualificados pela mensuração e avaliação em Psicologia (Hutz; Bandeira, 2003).

Tais esforços renderam ao cenário nacional a formação de grupos e institutos preocupados em estudar, pesquisar, desenvolver e regular a utilização de instrumentos psicológicos de medida. Só para citar alguns exemplos, existe no Brasil, em termos de organizações, o IBAP (Instituo Brasileiro de Avaliação Psicológica) e a SBRo (Sociedade Brasileira de Rorschach e outras Técnicas Projetivas); já em termos de laboratórios de pesquisa, podem ser citados, entre outros, o LabPAM (Laboratório de Pesquisa em Avaliação e Medida / UNB), o LabAPE (Laboratório de Avaliação Psicológica e Educacional / USF-SP), o LAMP (Laboratório de Avaliação e Medidas Psicológicas / PUC Campinas), o BNCS (Base Normativa do Comportamento Social / UFPB), o GEST (Grupo de Saúde Mental e do Trabalho / UFRN) e o LM (Laboratório de Mensuração / UFRS).

Apesar desse empenho atualmente observado, a situação dos testes psicológicos no Brasil ainda permanece delicada. Noronha, Primi e Alchieri (2004) constataram que, dos 146 instrumentos de avaliação psicológica comercializados atualmente no País, apenas 28,8\% oferecem estudos de precisão, validade e padronização. Buscando minimizar essa situação, recentemente os testes psicológicos utilizados no Brasil passaram por um processo de avaliação. $O$ Conselho Federal de Psicologia elaborou o SATPSI (Sistema de Avaliação dos Testes Psicológicos), por meio do qual foram analisados algo em torno de 140 testes utilizados no Brasil (maiores informações podem ser encontradas no site http:/ /www.pol.org.br/satepsi) com o objetivo de apontar os testes psicológicos em condições de uso. Esse monitoramento reflete uma clara preocupação com um elemento que já há muito é um caracterizador da profissão de psicólogo.

Face ao que foi comentado referente ao desenvolvimento dos testes psicológicos, e levando em consideração sua relevância no contexto da Psicologia, foi elaborado o objetivo principal do presente estudo, a saber, analisar a utilização dos testes psicológicos na produção científica brasileira nos últimos anos, especificamente entre os anos 2000 e 2004. A partir do presente estudo, espera-se poder traçar um panorama geral da utilização dos testes no contexto atual da produção de artigos científicos, notadamente, a prevalência do seu uso, a forma como são abordados bem como aspectos demográficos e institucionais vinculados à elaboração dos artigos analisados. Tal resultado pode ser alcançado em função da ampliação da disponibilidade de informações por meios digitais, possibilitando o aumento dos estudos bibliométricos em todas as áreas (Maia; Caregnato, 2004). A Psicologia, nesse contexto, não é uma exceção (ver, por exemplo, Bariani et al., 2004; Hutz; Bandeira, 1993; Passos, 2003; Souza; Gauer; Hutz, 2004; Yamamoto et al., 2002; Yamamoto; Souza; Yamamoto, 1999).

\section{Breves considerações históricas}

O surgimento e desenvolvimento dos testes psicológicos tiveram lugar no século XIX, sendo Francis Galton, James Cattel e Alfred Binet seus principais fundadores. Apesar das contribuições européias terem sido de grande importância em um momento inicial, os testes ganharam repercussão de forma bastante acentuada nos EUA, recebendo ali um valor muito mais proeminente (Boring, 1950). Posteriormente, o uso desse instrumental proliferou, e, atualmente, os testes são utilizados nos mais diversos países onde a Psicologia se faz presente.

Neste contexto, observa-se que o século XX presenciou uma constante utilização dos testes,
Apesar desse empenho atualmente observado, a situação dos testes psicológicos no Brasil ainda permanece delicada. Noronha, Primie Alchieri (2004) constataram que, dos 146 instrumentos de avaliação psicológica comercializados atualmente no País, apenas $28,8 \%$ oferecem estudos de precisão, validade e padronização. 
não apenas dos testes de aplicação individual, que eram mais demorados e demandavam maior trabalho, mas também os testes de aplicação coletiva. As duas grandes guerras mundiais colaboraram nesse sentido, uma vez que, nessas ocasiões, foram desenvolvidos testes direcionados para atender as necessidades da guerra, como escalas que pudessem rapidamente classificar milhares de recrutas em termos de suas aptidões e capacidades intelectuais.

A partir desse momento, na década de cinqüenta, especificamente, como bem aponta Fernándes-Balestros (1997), não há um só contexto de intervenção psicológica que não faça uso dos testes. Não obstante, como assinala esse mesmo autor, na década seguinte, nos EUA, os testes passaram a sofrer uma forte crítica pública, manifestada tanto na imprensa como nos tribunais. Tais críticas questionavam o valor científico dos testes bem como a suposta ilegalidade em sua administração, uma vez que tais construtos diziam respeito ao princípio constitucional da intimidade ou privacidade das pessoas. De acordo com Pasquali (1999), na segunda metade do século XX até os idos da década de 1980, os testes passaram por um período de sistematização que resultou em duas tendências antagônicas: os trabalhos de síntese e de crítica. Nesse período, a própria "American Psychological Association" - APA trabalhou no sentido de deixar claras as normas de elaboração e utilização dos testes.

Diante dessa realidade, observa-se que os testes psicológicos, desde a sua fundação até os dias atuais, difundiram-se imensamente, não apenas em países europeus (onde surgiram) ou nos EUA (onde ganharam maior expressividade), mas também em outros países, onde a Psicologia, enquanto disciplina científica, começava a se estruturar, como é o caso do Brasil (Baquero, 1974). No tópico a seguir, são exploradas algumas passagens históricas relevantes para o desenvolvimento dos testes no contexto brasileiro.

\section{Os testes psicológicos no Brasil}

A história dos testes psicológicos no Brasil confunde-se com a história da própria Psicologia enquanto ciência e profissão. Como já foi exposto ao citar o trabalho de Pereira e Neto (2003), os testes já figuravam no cenário nacional antes mesmo da profissionalização da Psicologia. Em uma perspectiva semelhante, Alchieri e Cruz (2003) também apontam alguns períodos do desenvolvimento histórico da Psicologia brasileira que foram marcados pela importância atribuída à avaliação psicológica e destacam momentos, como a produção médicocientífica acadêmica (1836-1930), em que as temáticas próprias da Psicologia começavam a aparecer academicamente na área médica, o estabelecimento e a propagação da Psicologia no ensino universitário (1930-1962), a criação dos cursos de graduação em Psicologia (19621987), a instalação dos cursos de pós-graduação (1970-1987), e, finalmente, em data mais recente, a criação dos laboratórios preocupados com testes psicológicos (1987- ). Todos esses períodos contêm valor tanto para o desenvolvimento do uso dos testes como também coincidem com o desenvolvimento da própria Psicologia.

Entretanto, em dado momento histórico, basicamente a partir da segunda metade do século passado, parece que os testes psicológicos e sua relevância começaram a ser questionados (Sisto; Sbardelini; Primi, 2001; Hutz; Bandeira, 2003). São levantadas dúvidas quanto à validade científica dos testes e questiona-se até mesmo a possibilidade ou legitimidade em se fazer medições de manifestações do psiquismo humano.

A esse respeito, Alchieri e Cruz (2003) comentam que, no final da década de 1960, observou-se um aumento do número dos cursos de Psicologia e houve, em conseqüência, uma crescente demanda de professores que se dedicassem mais intensamente ao ensino. Em função disso, teria ocorrido uma queda na qualidade da formação profissional dos 
psicólogos, notadamente na área da avaliação psicológica. Tal fato teria sido acompanhado por um desinteresse pela aprendizagem das técnicas de exames psicológicos e uma subestimação dos instrumentos de medida, bem como o seu conseqüente descrédito, com poucos esforços empreendidos no âmbito da pesquisa, construção ou adaptação desse material aos contextos nacionais.

Não obstante, a despeito de todas as críticas e do conseqüente desânimo, os testes nunca deixaram completamente de ser utilizados por profissionais e pesquisadores como instrumento de avaliação psicológica (Sisto; Sbardelini; Primi, 2001). No cenário nacional, uma retomada mais consistente no interesse pelos testes psicológicos ocorreu a partir de 1980 (Alchieri; Cruz, 2003; Hutz; Bandeira, 2003; Noronha; Vendramine, 2003). Tal recuperação pode ser observada através do desenvolvimento de laboratórios de testes psicológicos em várias universidades brasileiras, do aumento do número de instrumentos psicológicos em uso e maior preocupação com suas qualidades psicométricas, de maior quantidade de estudos sobre a avaliação psicológica em eventos científicos nacionais, além da realização de simpósios e congressos específicos nessa área. Para Cruz, Alchieri e Sardá Jr. (2002), essa ampliação no interesse pelos testes, especialmente na literatura, tem repercussões na prática profissional, na medida em que possibilita um aperfeiçoamento na qualidade da intervenção do psicólogo nos mais diversos contextos, além de permitir sua inclusão em outras áreas de atuação. Contudo, como ressaltam Hutz e Bandeira (1993), apesar de se observar, no âmbito brasileiro, uma produção crescente no campo dos testes psicológicos, há lacunas a serem preenchidas. Com base em levantamento realizado em alguns dos principais periódicos científicos brasileiros e internacionais de Psicologia, no intervalo entre 1977 e 1992, aproximadamente, Hutz e Bandeira (1993) observaram, entre outras coisas, que instrumentos muito comuns na literatura internacional não foram encontrados no Brasil; ademais, ressaltam que muitos dos principais testes objetivos utilizados internacionalmente para a avaliação da personalidade, inteligência, memória, assim como baterias neuropsicológicas, não tiveram, até então, sua adaptação e normatização efetuadas para o contexto nacional. Diante dessa realidade, cabe indagar até que ponto a literatura científica brasileira tem fornecido contribuições relativas e/ou baseadas nos testes psicológicos.

Em face dessa questão, como já mencionado, o presente estudo tem como objetivo principal verificar a expressividade do uso dos testes no cenário nacional, analisando particularmente a produção de artigos científicos na área da Psicologia. A partir dessa análise, busca-se verificar o predomínio do uso dessa ferramenta bem como as especificidades demográficas e institucionais envolvidas no interesse dessas produções. Nesse sentido, os objetivos específicos desta pesquisa foram: a) analisar a proporção que há entre as publicações de outras temáticas e as que envolvem os testes psicológicos, discriminando os artigos que tratam essa temática de forma direta e indireta; b) analisar a natureza (teórica ou empírica) desses artigos; c) observar como se distribui a produção, quanto à utilização dos testes psicológicos, entre as Regiões brasileiras (Centro-Oeste, Nordeste, Norte, Sudeste e Sul) e os países estrangeiros; d) verificar como se distribui a produção quanto ao tipo de instituição (federal, estadual, privada, etc.) bem como observar quais são as instituições que mais têm artigos direcionados aos testes psicológicos, e, finalmente, e) observar a predominância dos autores quanto ao sexo, analisando também as freqüências de autoria única e co-autoria na elaboração desses artigos.

\section{Método}

Amostra

A produção analisada foi constituída por todos os artigos de periódicos brasileiros na área de 
Psicologia, compreendidos num intervalo de cinco anos (entre 2000 e 2004), que estavam disponíveis na base Periódicos Capes (www.periodicos.capes.gov.br), basicamente na primeira quinzena de fevereiro de 2005. No total, foram analisadas dezoito revistas: Estudos de Psicologia ( $R N)$, Interações: Estudos e Pesquisas em Psicologia, Memorandum: Memória e História da Psicologia, Psicologia Clínica, Psicologia e Sociedade, Psicologia em Estudo, Psicologia USP, Psicologia: Ciência e Profissão, Psicologia: Reflexão e Crítica, Psicologia: Teoria e Pesquisa, Psicologia: Teoria e Prática, Psicólogo inFormação, Psychê: Revista de Psicanálise, Pulsional Revista de Psicanálise, Revista de Psicologia Escolar e Educacional, Revista Latinoamericana de Psicopatologia Fundamental, Revista Estudos Feministas e Revista Mal-Estar e Subjetividade.

Todos esses periódicos atendiam a quatro exigências feitas pela diretoria da CAPES (Coordenação de Aperfeiçoamento de Pessoal de Nível Superior), a saber: a) serem revistas nacionais com circulação local, nacional e internacional; b) serem classificadas com o nível A e/ou B; c) possuírem artigos completos com formato eletrônico, e d) estarem disponíveis gratuitamente na internet.

No total, foram analisados 1182 artigos, sendo a média de artigos analisados, por revista, de 65,7 . Não obstante, cabe destacar que algumas revistas não dispunham de todos os seus artigos compreendidos na base aqui considerada. Nesse sentido, desconsiderando as revistas que tiveram menos de dez artigos disponíveis (Interações: Estudos e Pesquisas em Psicologia, Psicologia Clínica, Psicólogo inFormação, Psychê: Revista de Psicanálise, Pulsional: Revista de Psicanálise e Revista Latinoamericana de Psicopatologia Fundamental), a média de artigos por revista sobe para 98,5, o que expressa um valor mais próximo do real comparado com o valor da média que considera todas as revistas.

Procedimento de coleta dos dados

Para a seleção dos artigos, foi acessada a base de artigos Periódicos Capes. Nesta, os títulos podem ser elencados conforme a disciplina de interesse. Dessa forma, selecionou-se a área de Psicologia, o que disponibilizou uma série de periódicos, dos quais foram selecionados apenas os brasileiros. Um a um, em cada periódico, foram analisados todos os artigos, compreendidos entre os anos 2000 e 2004, que se encontravam disponíveis no período da coleta (03 a 16 de fevereiro de 2005).

Inicialmente, frente a cada artigo, era observado se havia sido utilizado algum tipo de teste psicológico. Em caso negativo, efetuava-se o registro dessa ausência. Já em caso afirmativo, um protocolo era preenchido a fim de colher alguns dados. Especificamente, buscou-se levantar as seguintes informações: 1) o ano de publicação do artigo; 2) a caracterização do uso do teste no artigo quanto ao foco, ou seja, se o artigo havia se centrado diretamente na temática dos testes, este era classificado como um uso direto: por outro lado, caso o artigo apenas utilizasse um ou mais testes para atingir o objetivo a que se propôs, recebia a classificação de uso indireto dos testes; 3 ) a identificação do estudo enquanto de natureza teórica ou empírica; 4) a(s) instituição(ões) à(s) qual(is) o(s) autor(es) estava(m) afiliado(s), identificando o tipo da instituição que poderia ser classificada como federal, estadual, privada, estrangeiras e outras (instituições que não eram eminentemente de ensino, como hospitais, por exemplo), bem como a(s) as Região(ões) na(s) qual(is) a(s) instituição(ões) se encontrava(m) (Centro-Oeste, Nordeste, Norte, Sudeste, Sul e países estrangeiros), e, por fim, 5) a quantidade e o sexo do(s) autor(es), podendo ser masculino, feminino ou não identificado (quando não era possível inferir o sexo com base no nome do autor). Uma vez colhidas essas informações num artigo, passava-se a analisar o próximo artigo. Dessa maneira, foram contemplados todos os volumes disponíveis no intervalo de anos pretendido.

Resultados

Os resultados agora descritos serão, por razões de ordem didática, distribuídos em três partes. 
Na primeira delas, encontra-se a descrição geral dos artigos que consideram testes psicológicos. Em seguida, é demonstrado como essa produção se distribui em termos geográficos e institucionais. Por fim, são apresentados alguns dados sobre a natureza da autoria desses trabalhos.

\section{Proporção, foco e natureza}

Depois de se consultar os 1182 artigos, disponíveis na base Periódicos Capes entre os anos 2000 e 2004, buscou-se identificar quais eram aqueles que consideravam e os que não consideravam testes psicológicos em seu corpo. Foi observada uma predominância dos artigos que não consideram nenhum teste psicológico $(80,5 \%)$. Apenas 230 artigos (19,5\%) consideravam, de alguma forma, os testes. Como já se pode perceber, a diferença entre o grupo de artigos que utilizou e o que não utilizou testes foi significativa $\left(X^{2}=441,02 ; g l=1 ; p\right.$ $<0,001)$. A proporção é de, aproximadamente, quatro para um, ou seja, para cada artigo que considera algum teste psicológico, há quatro que não lidam com nenhum teste desse tipo.

Dentre aqueles artigos que consideravam os testes psicológicos, foram observados quais eram os que enfocavam os testes de forma direta, isto é, o foco central do artigo era a temática dos testes psicológicos, a exemplo dos artigos de validação de escalas. Também foram observados artigos que utilizavam os testes, mas só de forma indireta, como, por exemplo, se o trabalho buscava conhecer a relação entre duas variáveis; para mensuração das mesmas, foram levadas em conta duas escalas, e o trabalho focalizava os testes indiretamente. Encontrouse uma equivalência, estatisticamente evidenciada $\left(X^{2}=0,07 ; g l=1 ; p>0,05\right)$, entre os artigos que utilizam direta $(49,1 \%) \mathrm{e}$ indiretamente $(50,9 \%)$ os testes. Poder-se-ia pensar, tendo em vista que uma das finalidades dos testes é a investigação de fenômenos psicológicos, que seriam mais freqüentes na literatura os trabalhos que utilizavam os testes indiretamente, entretanto, como se constatou, houve uma paridade entre os dois grupos.

Quanto à natureza (teórica ou empírica) desses trabalhos, foram diferenciados os estudos que envolviam algum tipo de coleta de dados e aqueles que estritamente tratavam de aspectos teóricos relativos aos testes. Como já seria esperado, a grande maioria dos artigos era de natureza empírica $(85,5 \%)$. Estes foram significativamente maiores que os artigos de natureza teórica $\left(X^{2}=122,71 ; g l=1 ; p<\right.$ $0,001)$. A finalidade primeira dos testes psicológicos é a coleta de informações sobre a realidade, e, nesse sentido, é coerente que as pesquisas busquem, predominantemente, enfocar a utilização dos testes nessa perspectiva.

\section{Distribuição geográfica e institucional}

Quanto à distribuição geográfica dos artigos que contemplaram os testes psicológicos, foram observados as cinco Regiões geopolíticas brasileiras e países estrangeiros. A atribuição regional foi feita com base na(s) instituição(ões) a(s) qual(is) o(s) autor(es) era(m) afiliado(s). Não raro, existiam artigos nos quais havia mais de um autor, e estes pertenciam a instituições diferentes; nesses casos, se a instituição fosse da mesma Região, o registro era apenas um, entretanto, se as instituições fossem de duas Regiões diferentes, efetuavam-se dois registros, um para cada Região, e assim por diante. Em função disso, a quantidade de registros foi maior que a quantidade de artigos analisados.

Pôde-se observar que, predominantemente, a Região Sudeste $(47,51 \%)$ reúne quase metade da produção nacional, notadamente o Estado de São Paulo, concentração essa evidenciada pela diferença significativa entre todas as Regiões $\left(X^{2}=194,33 ; g l=5 ; p<0,001\right)$. Na seqüência, num mesmo patamar, observam-se os países estrangeiros (14,94\%), a Região Centro-Oeste $(12,26 \%)$, a Região Sul $(11,88 \%)$ e a Região 
Nordeste (11,49\%); em último lugar, encontrase a Região Norte $(1,92 \%)$. A diferença estatística deve-se, fundamentalmente, à predominância de artigos oriundos da Região Sudeste.

Tendo sido feita a análise geográfica, seria agora interessante observar que tipos de instituição são predominantes. O registro foi semelhante ao do caso anterior. Observou-se uma hierarquia numérica, na qual lideravam as instituições federais (36,04\%), seguidas das privadas $(31,10 \%)$, estaduais $(18,02 \%)$, estrangeiras $(13,43 \%)$ e, minoritariamente, outras $(1,41 \%)$, a exemplo de algumas fundações, hospitais e institutos de pesquisa. Com relação ao contraste estatístico, destacase que não houve diferença entre as federais e as privadas $\left(\mathrm{X}^{2}=1,03 ; \mathrm{gl}=1 ; p>0,05\right) \mathrm{e}$ entre as estaduais e estrangeiras $\left(\mathrm{X}^{2}=1,9\right.$; $\mathrm{gl}$ $=1 ; p>0,05)$. Por outro lado, observaram-se diferenças entre as federais, estaduais e estrangeiras $\left(\mathrm{X}^{2}=35,95 ; \mathrm{gl}=2 ; p<0,001\right)$, as privadas, estaduais e estrangeiras $\left(X^{2}=\right.$ $22,81 ; \mathrm{gl}=2 ; p<0,001)$, e entre as privadas e as estaduais $\left(\mathrm{X}^{2}=9,85 ; \mathrm{gl}=1 ; p<0,01\right)$.

Buscou-se, também, além do tipo de instituição, mapear as instituições propriamente ditas que figuraram nos artigos que contemplavam testes. A forma de registro também é semelhante à dos dois casos anteriores. Verificou-se que a instituição mais produtiva na área de testes psicológicos foi a Universidade de São Francisco - USF $(f=30)$, seguida pela Universidade de Brasília - UnB ( $f$ = 26), Universidade de São Paulo - USP ( $f=$ 24), Universidade Federal da Paraíba - UFPB ( $f=16$ ), Pontifícia Universidade Católica de Campinas - PUC-CAMP $(f=14)$ e Universidade Federal do Rio Grande do Sul UFRS $(f=10)$.

\section{Natureza da autoria}

Finalmente, neste tópico, analisa-se um elemento mais particular, a autoria dos artigos em questão, particularmente o sexo dos autores e a predominância de trabalhos com autoria única e co-autoria. Deve-se lembrar que muitos trabalhos são realizados em sistema de parceria, logo, é natural que a quantidade de autores seja maior que a quantidade dos artigos considerados. Dessa maneira, ao longo dos 230 artigos que tratavam de testes, trabalharam um total de 591 autores. Destes, a predominância do sexo feminino é marcante e significativa, comparando-se com o sexo masculino $\left(X^{2}=\right.$ $66,36 ; \mathrm{gl}=1 ; \mathrm{p}<0,001)$ : mais da metade da participação nos artigos é de mulheres (64,97\%). Convém mencionar que apenas 3,05\% dos autores não tiveram o seu sexo inferido com base no nome.

No que tange ao aspecto da autoria única ou múltipla, a grande maioria dos trabalhos é feita com a presença de co-autores (75,65\%), significativamente superior à freqüência daqueles trabalhos de autoria única $\left(X^{2}=60,54\right.$; $\mathrm{gl}=1 ; \mathrm{p}<0,001)$. Cabe destacar, como informação complementar, que é de 2,57 (DP $=1,53$ ) a quantidade média de autores por artigo.

\section{Discussão}

O presente estudo buscou traçar um perfil da utilização dos testes psicológicos na literatura científica brasileira nos últimos anos. Em termos gerais, buscou-se fornecer uma contribuição no sentido de se analisar como a Psicologia vem sendo conduzida atualmente e, mais especificamente, como a Psicologia vem lidando com os testes psicológicos. Estudos bibliométricos como este são relevantes na medida em que permitem uma visualização do andamento de um dado ramo do saber.

Entretanto, é necessário ter em mente ao menos duas limitações deste estudo. Em primeiro lugar, a análise limitou-se a um contexto muito específico: a produção de periódicos científicos reunidos na base Periódicos Capes. Há outros contextos em que essa mesma análise poderia 
ser feita, por exemplo, a produção de livros sobre o assunto, que tem crescido visivelmente nos últimos anos, a freqüência da comercialização dos testes, o seu uso nos mais variados âmbitos, entre outros. Em segundo lugar, destaca-se que outras revistas relevantes de Psicologia não foram analisadas, dado a dificuldade de acesso em função da sua não disponibilidade em formato eletrônico, bem como a indisponibilidade de alguns volumes de determinados periódicos que se encontravam disponíveis no referido formato. Diante do exposto, pode-se concluir que tanto uma análise da utilização dos testes em outros contextos como a inclusão dos artigos indisponíveis no formato eletrônico, no momento da coleta, certamente favoreceriam uma estimativa mais acurada e ainda mais próxima da realidade bem como uma visão mais completa de seu status no quadro atual da Psicologia brasileira. Não obstante, os resultados aqui apresentados permitem a visualização geral de elementos em torno da utilização do uso dos testes atualmente.

Inicialmente, no que se refere à prevalência de uso de testes psicológicos no conjunto dos artigos analisados nos cinco anos considerados (2000-2004), os resultados revelam que a predominância é dos artigos que não consideram nenhum teste. A proporção é de, aproximadamente, quatro para um, com uma equivalência entre os artigos que utilizam direta e indiretamente os testes, sendo a grande maioria artigos de natureza empírica.

Levando em conta esses dados, é plausível pensar que há atualmente uma tendência geral na literatura brasileira a não priorizar a utilização de testes psicológicos. Em Psicologia, muitas são as questões, bem como muitas são as formas metodológicas de abordá-las, e os testes compõem uma via metodológica para a coleta de informações sobre os fenômenos psicológicos, contudo, não é a única, mesmo porque há problemas de pesquisa que os testes não conseguiriam resolver. Considerando que, em parte, dos artigos aqui analisados, as questões levantadas não se prestavam a ser resolvidas por meio dos testes, mas que, por outro lado, em grande parte dos artigos, os testes poderiam ser utilizados e, não obstante, por razões de preferência metodológica, não o foram, é possível concluir pela existência de um forte indício da pouca preferência pelos testes como instrumental de pesquisa no âmbito da Psicologia brasileira. Pode-se afirmar, portanto, que o cenário de uma adequada utilização dos testes psicológicos, no Brasil, ainda é incipiente, tal como também observado em estudos anteriores (Hutz; Bandeira, 1993; Noronha; Primi; Alchieri, 2004).

Com relação ao volume de artigos que utilizaram testes, também se observou uma paridade entre os que utilizaram os testes de forma direta e indireta, o que denota um igual interesse entre a aplicação e o estudo ou regulação desse instrumento. Essa observação expressa um interesse válido em canalizar esforços na direção de estudos que aprimoram teórica e metodologicamente o uso dos testes.

No que tange ao fato de a maioria dos artigos ter sido de natureza empírica, pode-se apontar que a finalidade primeira dos testes psicológicos é a coleta de informações sobre a realidade e, nesse sentido, é coerente que as pesquisas busquem predominantemente enfocar a utilização dos testes nessa perspectiva.

Quanto à distribuição geográfica e institucional da produção analisada, observou-se que a maior concentração se situa na Região Sudeste e que houve uma equivalência entre as universidades federais e privadas. Ademais, no topo da relação das instituições mais produtivas na temática dos testes psicológicos, figuraram a Universidade de São Francisco, seguida pela Universidade de Brasília, Universidade de São Paulo, Universidade Federal da Paraíba, Pontifícia Universidade Católica de Campinas e Universidade Federal do Rio Grande do Sul.

Tais achados possibilitam algumas reflexões. Primeiramente, a concentração da produção de 
artigos que consideram testes psicológicos na Região Sudeste reproduz o mesmo fenômeno observado por Yamamoto, Souza e Yamamoto (1999), que, analisando periódicos científicos de Psicologia entre 1990 e 1997, chegaram a um resultado semelhante. O maior volume de produção na referida Região não é causal, e reflete uma relação com a maior concentração de recursos disponíveis e maior volume de pesquisadores estabelecidos nessa Região.

Como se pôde constatar, as universidades federais mantêm a tradição de permanecerem à frente na esfera da pesquisa e da produtividade científica. Não obstante, as instituições particulares, que têm um histórico pautado prioritariamente no ensino, começam a despontar de forma significante no cenário da produção científica, ao menos no campo aqui tratado, chegando a equiparar-se às instituições anteriores.

No que tange ao grupo das instituições mais produtivas, cabe mencionar que quase a totalidade das instituições citadas tem uma trajetória marcada pelo interesse na área de avaliação psicológica, interesse que inclusive rendeu, ao cenário nacional, a formação de laboratórios, linhas de pesquisa, grupos de estudo e institutos preocupados em estudar, pesquisar, desenvolver e regularizar a utilização de instrumentos psicológicos de medida. Esses elementos foram e ainda são responsáveis cruciais pela valorização dos testes no cenário nacional (Alchieri; Cruz, 2003).

Finalmente, no que diz respeito à natureza da autoria, a predominância foi dos trabalhos com a autoria feminina e com a participação de coautores. A maioria feminina reflete uma tendência geral da Psicologia brasileira, que é a de possuir, em seus quadros, uma predominância do sexo feminino, como demonstraram Yamamoto, Souza e Yamamoto (1999). O acentuado predomínio de publicações em sistema de co-autoria pode expressar, nessa área, um indicador de igualdade na relação entre a produção do conhecimento e sua publicação. Ademais, o sistema de co-autoria atua como elemento facilitador que viabiliza a produção. Nessa direção, Hutz e Bandeira (2003) indicam que a cooperação entre pesquisadores vem sendo uma prática utilizada para minimizar as dificuldades nas pesquisas no campo dos testes.

\section{Considerações finais}

A utilização de testes é um caracterizador marcante na história da Psicologia. O conhecimento advindo com base em testes, uma vez que estes sejam válidos e precisos, é confiável, pois baseia-se essencialmente em evidências empíricas e não apenas em meras especulações (Anastasi; Urbina, 2000), o que justifica salientar a necessidade de ampliar e aprimorar ainda mais o debate a respeito do uso dessas ferramentas no âmbito nacional. É possível perceber atualmente um movimento de re-valorização dos testes no Brasil, entretanto, a produção científica nessa área parece ainda ser modesta, tanto no que se refere à abordagem direta do assunto quanto à própria utilização dos testes enquanto instrumental de pesquisa.

Baquero (1974), três décadas atrás, já apontava três atitudes que poderiam ser evocadas diante dos testes psicológicos. Pode-se dizer que as duas primeiras se caracterizam por um certo extremismo: enquanto a primeira considera os testes infalíveis e inequívocos, a segunda, por outro lado, expressa um descrédito para com os instrumentos e afirmam que os mesmos para nada servem. A terceira atitude foi chamada de atitude lógica diante dos testes. Nessa perspectiva, os testes são assumidos como uma eficaz fonte de informação que deve ser considerada e tomada de forma cautelosa, associando-se ainda a outras fontes.

Concordando aqui com essa terceira posição, conclui-se que os testes, assim como qualquer outro instrumento de medida, possuem imprecisões. Entretanto, não se joga um relógio de pulso fora apenas porque ele atrasa um 
segundo por dia. É claro que a precisão de um relógio na medição do tempo ainda é um pouco distante da medição de um construto realizada por um teste, mas os primeiros relógios não foram os atômicos (que são mais precisos por se basearem em certas propriedades dos átomos e terem a margem de erro de um segundo a cada um bilhão de anos), e os testes estão extremamente distantes dessa acurácia. Entretanto, considerando o fato de a Psicologia ser uma ciência de idade muito tenra quando comparada à Física, por exemplo, pode-se fazer uma analogia na qual os testes psicológicos corresponderiam cronologicamente aos relógios de água ou às famosas ampulhetas, que foram, por muito tempo, os instrumentos desenvolvidos para a medição do tempo.

Muito há que ser feito ainda, mas nem por isso se deve descartar o que se tem de melhor neste momento. Tratar os testes em função de sua utilidade, mas considerando as suas limitações, é a atitude lógica que se deve ter frente a eles. O ímpeto e os esforços deveriam ser, ao lado da crítica qualificada e construtiva, o de se trabalhar no desenvolvimento de um instrumental mais acurado e eficaz.

Marcilio Lira de Souza Filho Mestrando em Psicologia cognitiva pela Universidade Federal de Pernambuco. Rua Enfermeira Ana Maria Barbosa de Almeida, 187, Jardim Cidade Universitária, 58052-270, João Pessoa - Paraíba. E-mail: liradesouza@yahoo.com.br.

Raquel Belo

Mestre em Psicologia social e professora pela Universidade Federal da Paraíba.

Valdiney Veloso Gouveia

Doutor em Psicologia pela Universidade Complutense de Madrid. Professor da Universidade Federal da Paraíba.

Recebido 01/02/06 Aprovado 24/06/06

ALCHIERI, J.C.; CRUZ, R. M. Avaliação Psicológica: Conceito, Métodos e Instrumentos. São Paulo: Casa do Psicólogo, 2003.

ANASTASI, A.; URBINA, S. Testagem Psicológica. Porto Alegre: Artes Médicas, 2000.

BAQUERO, M. G. Testes Psicométricos e Projetivos: Medidas Psicoeducativas. São Paulo: Loyola, 1974.

BARIANI, I. C. D.; BUIN, E., BARROS, R. C.; ESCHER, C. A. Psicologia Escolar e Educacional no Ensino Superior: Análise da Produção Científica. Psicologia Escolar e Educacional, v. 8, n. 1, pp. 17-27, 2004.

BORING, E. G. A History of Experimental Psychology. Nova York: Appleton-Century-Crofts, 1950.

CRUZ, R. M.; Alchieri, J. C.; SARDA JR. J. J. Avaliacão e Medidas Psicológicas: Producão do Conhecimento e da Intervenção Profissional. Casa do Psicólogo: São Paulo, 2002.

FERNÁNDEZ-BALLESTROS, R. Evaluación Psicológica y Testes. In: Cordero, A. (org.). La Evaluación Psicológica en el Año 2000. Madrid: TEA Ediciones, 1997, pp. 11-27.

HUTZ, C. S.; BANDEIRA, D. R. Tendências Contemporâneas no Uso de Testes: uma Análise da Literatura Brasileira e Internacional. Psicologia: Reflexão e Crítica, 6(1/2), pp. 85-101, 1993.

Avaliação Psicológica no Brasil Situação Atual e Desafios para o Futuro. In: Yamamoto, O. H.; Gouveia, V. V. (org.). Construindo a Psicologia Brasileira: Desafios da Ciência e Prática Psicológica. São Paulo: Casa do Psicólogo, 2003, pp. 261-277.

MAIA, M. F. S.; CAREGNATO, S. Estudos Bibliométricos na Comunidade Científica: Bibliotecas Digitais como Fator de Revitalização. Trabalho apresentado no XIV ENDOCOM (Encontro de Informação em Ciências da Comunicação), Porto Alegre, RS, 2004.

NORONHA, A. P. P.; VENDRAMINI, C. M. M. Parâmetros Psicométricos: Estudo Comparativo entre Testes de Inteligência e de Personalidade.
Psicologia: Reflexão e Crítica, v. 16, n. 1, pp. 177-182, 2003.

NORONHA, A. P.P.; PRIMI, R.; ALCHIERI, J. C. Parâmetros Psicométricos: uma Análise de Testes Psicológicos Comercializados no Brasil. Psicologia: Ciência e Profissão, v. 24, n. 4, pp. 88-99, 2004.

PASQUALI, L. Instrumentos Psicológicos: Manual Prático de Elaboração. Brasília: LabPAM, 1999.

PASSOS, I. C. F. Cartografia da Publicação Brasileira em Saúde Mental: 1980-1996. Psicologia: Teoria e Pesquisa, v. 19, n. 3, pp. 231-240, 2003.

PEREIRA, F.M.; NETO, A. P.OPsicólogo no Brasil: Notas sobre seu Processo de Profissionalização. Psicologia em Estudo, v. 8, n. 2, pp. 19-27, 2003.

ROSAS, P. O Discurso Psicológico na SBPC. Recife: Editora da Universidade Federal de Pernambuco, 1998.

SISTO, F. F.; SBARDELINI, E. T. B.; PRIMI, R. Contextos e Questões da Avaliação Psicológica. São Paulo: Casa do Psicólogo, 2001.

SOUZA, L. K.; GAUER, G.; HUTZ, C. S. Publicações em Psicologia do Desenvolvimento em dois Periódicos Nacionais na Década de 1990 Psico Usf, v. 9, n. 1, pp. 49-57, 2004

TYLER, L. E. Testes e Medidas. $3^{\text {a }}$ ed. Rio de Janeiro: Zahar, 1973.

VAN KOLCK, O. L. Técnicas de Exames Psicológicos e suas Aplicações no Brasil. Petrópolis: Vozes, 1974.

YAMAMOTO, O.H.: MENANDRO, P.R.M.: KOLLER,S.H.: LOBIANCO, A.C.; HUTZ, C. S.; BUENO, J. L. O.; GUEDES, M. C. Avaliaçãode Periódicos Científicos Brasileiros da Área da Psicologia. Ciência da Informação, v. 31, n. 2 , pp. 163-177, 2002

YAMAMOTO, O. H.; SOUZA, C. C.; YAMAMOTO, M. E. A Produção Científica na Psicologia: uma Análise dos Periódicos Brasileiros no Período 1990-1997. Psicologia Reflexão e Crítica, v. 12, n. 2, pp. 549-565, 1999. 